ALVES, Fábio; ABREU, Claudia; SCHROEDER, Tania; CARVALHO, Marco; ESTRADA, Adrian; SOLIGO, Valdecir; SILVA, Luzia.

\title{
PROJETO BEZALEL: UM ENSAIO DE ANTROPOLOGIA VISUAL NO BAIRRO SANGA FUNDA EM CASCAVEL - PR
}

\author{
Bezalel project: a visual anthropology essay in the neighborhood sanga funda from \\ Cascavel, Paraná, Brazil
}

Fábio Lopes Alves ${ }^{1}$

Claudia Barcelos de Moura Abreu. ${ }^{2}$

Tania Maria Rechia Schroeder ${ }^{3}$

Marco Antonio Batista Carvalho. ${ }^{4}$

Adrian Alvarez Estrada ${ }^{5}$

Valdecir Soligo ${ }^{6}$

Luzia Batista de Oliveira e Silva?

http://dx.doi.org/10.52641/cadcaj.v7i1.649

RESUMO: Neste ensaio visual, é descrito parte dos resultados de uma transformação artística que ocorreu no bairro Sanga Funda, em Cascavel - PR por meio do projeto "Bezalel: arte que transforma". A proposta consistiu em colorir o bairro por meio de revitalização de algumas residências através de pinturas e da arte do graffiti. Para tal, o projeto contou com a participação de diversos artistas, oriundos de diferentes estados do Brasil, na qual todos tinham algo em comum: a ação voluntária. A Associação Além da Arte, por meio de parcerias com a Secretaria de Cultura do Município de Cascavel, Associação de Moradores, Central Única das Favelas e Coral Tintas, se responsabilizou em adquirir as ferramentas e insumos necessários à execução da proposta.

PALAVRAS-CHAVES: Antropologia Visual, Bairro Sanga Funda, Projeto Bezalel, Graffiti, Cascavel - PR

\footnotetext{
${ }^{1}$ Professor do Programa de Pós-Graduação em Sociedade, Cultura e Fronteiras da Universidade Estadual do Oeste do Paraná. https://orcid.org/0000-0002-2114-3831

2 Professora do Programa de Pós-Graduação em Educação da Universidade Federal de São Paulo. https://orcid.org/0000-0001-8814-1235

3 Professora do Programa de Pós-Graduação em Educação da Universidade Estadual do Oeste do Paraná. https://orcid.org/0000-0002-3646-3088

4 Professor do Programa de Pós-Graduação em Educação em Ciências e Educação Matemática da Universidade Estadual do Oeste do Paraná. https:// orcid.org/0000-0002-6811-2661

${ }^{5}$ Professor do Programa de Pós-Graduação em Educação da Universidade Estadual do Oeste do Paraná. https://orcid.org/0000-0002-0980-8925

${ }^{6}$ Professor do Programa de Pós-Graduação em Educação da Universidade Estadual do Oeste do Paraná. https://orcid.org/0000-0003-2618-009X

${ }^{7}$ Pó-doutorado, Faculdade de Filosofia da Universidade de Borgonha - Dijon/França. https://orcid.org/0000-00034880-7199
} 
ABSTRACT: In this visual essay, part of the results of an artistic transformation that took place in the Sanga Funda neighborhood, in Cascavel - PR, is described through the project "Bezalel: art that transforms". The proposal consisted of coloring the neighborhood by revitalizing some residences through paintings and graffiti art. To this end, the project had the participation of several artists, from different states of Brazil, in which all had something in common: the voluntary action. "Além da Arte" (Beyond Art) Association, through partnerships with the Cascavel Municipal Secretariat of Culture, Residents' Association, "Central Única das Favelas" (Favelas Unique Center) and "Tintas Coral" (Coral Paints), was responsible for acquiring the tools and supplies needed for the execution of the proposal.

KEYWORDS: Visual Anthropology, Sanga Funda Neighborhood, Bezalel Project, Graffiti, Cascavel - PR.

O Sanga Funda se constitui num conjunto de moradias populares localizado no bairro homônimo localizado na zona norte de Cascavel - PR, composto por aproximadamente 180 famílias, que formam a base da pirâmide social, classes C, D e E (BARBOZA, 2017) e que, anteriormente, residiam de forma irregular no bairro Jardim Gramado. Sua criação é, portanto, resultado de uma longa reivindicação do Movimento Nacional de Luta por Moradia (MNLM). A área do bairro atualmente é dividida entre área construída e área de preservação ambiental.

Em 2019 a Associação Além da Arte elaborou e executou um projeto de transformação do Sanga Funda em atrativo turístico, intitulado Bezalel. A proposta consistiu em colorir o bairro por meio de revitalização de algumas residências através de pinturas e da arte do graffiti. Para tal, o projeto contou com a participação de diversos artistas, oriundos de diferentes estados do Brasil, na qual todos tinham algo em comum: a ação voluntária. A Associação Além da Arte, por meio de parcerias com a Secretaria de Cultura do Município de Cascavel, Associação de Moradores, Central Única das Favelas e Coral Tintas, se responsabilizou em adquirir os insumos e ferramentas necessárias à execução da proposta. Desse modo, as famílias do bairro Sanga Funda que disponibilizaram as paredes das residências para se tornarem telas nas mãos nos artistas, não precisaram arcar com nenhum custo financeiro. Apenas ofereceram alimentação e hospedagem aos grafiteiros. Durante a pesquisa de campo, os autores deste ensaio, perceberam que era muito comum os artistas receberem diversos convites de alimentação ou hospedagem. Isso demonstra a satisfação dos moradores com a ação.

A origem do nome do projeto, Bezalel: arte que transforma, é uma alusão ao contido em no livro de Êxodo, capítulo 31 e versículo 3, que diz: "Eu fiz que ficasse pleno do Espírito de Deus em sabedoria, entendimento e capacidade artística". O sociólogo da Université de Sorbonne, Michel Maffesoli, quando esteve em Cascavel, no mesmo ano, para ministrar conferência junto à Associação Comercial e Industrial da cidade (ACIC), foi ao bairro Sanga Funda conhecer as 
transformações que ali ocorreram por meio da Arte. Os integrantes do Laboratório de Antropologia Visual da Universidade Estadual do Oeste do Paraná (UNIOESTE), ao realizarem uma etnografia visual (CIDADE, 2018, KOURY, 1998, 1999a, 1999b, 2001, 2014) do projeto Bezalel, registraram mais de 900 imagens, das quais foram selecionadas 15, que são apresentadas neste ensaio visual. No presente ensaio visual, conforme problematizado em (ALVES, et al, 2021) seguimos a proposta teórico-metodológica da fotoetnografia que consiste em utilizar a fotografia como forma de narrativa integral (Achutti, 2004, p. 74), sem a necessidade de textos, seja na forma de legenda, seja com comentários entre uma imagem e outra. De acordo com Achutti e Hassen (2004, p. 276), o que caracteriza a fotoetnografia é quando o uso da fotografia, em pesquisas etnográficas, deixa de ser meramente ilustrativo e passa a assumir a centralidade da narrativa.

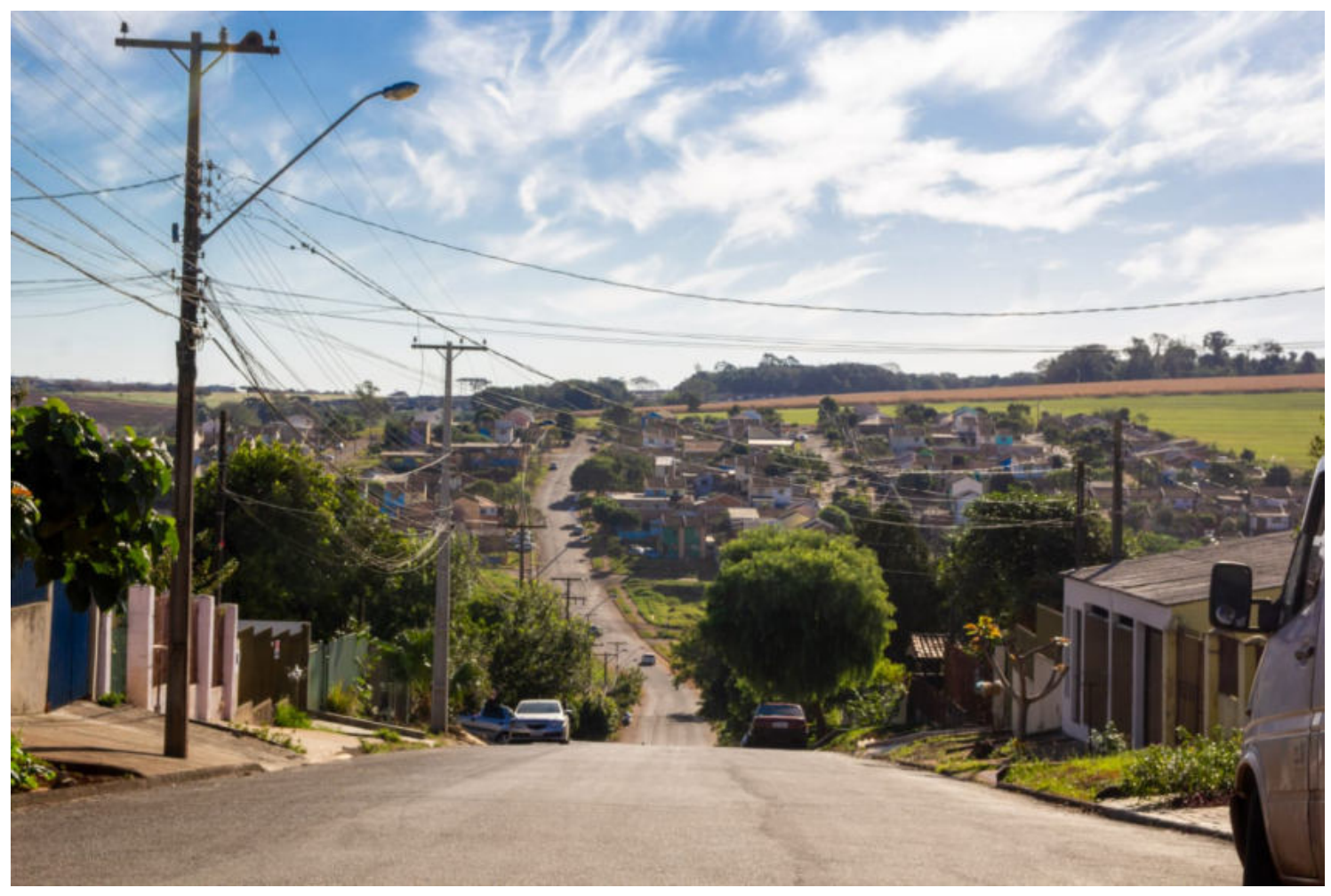




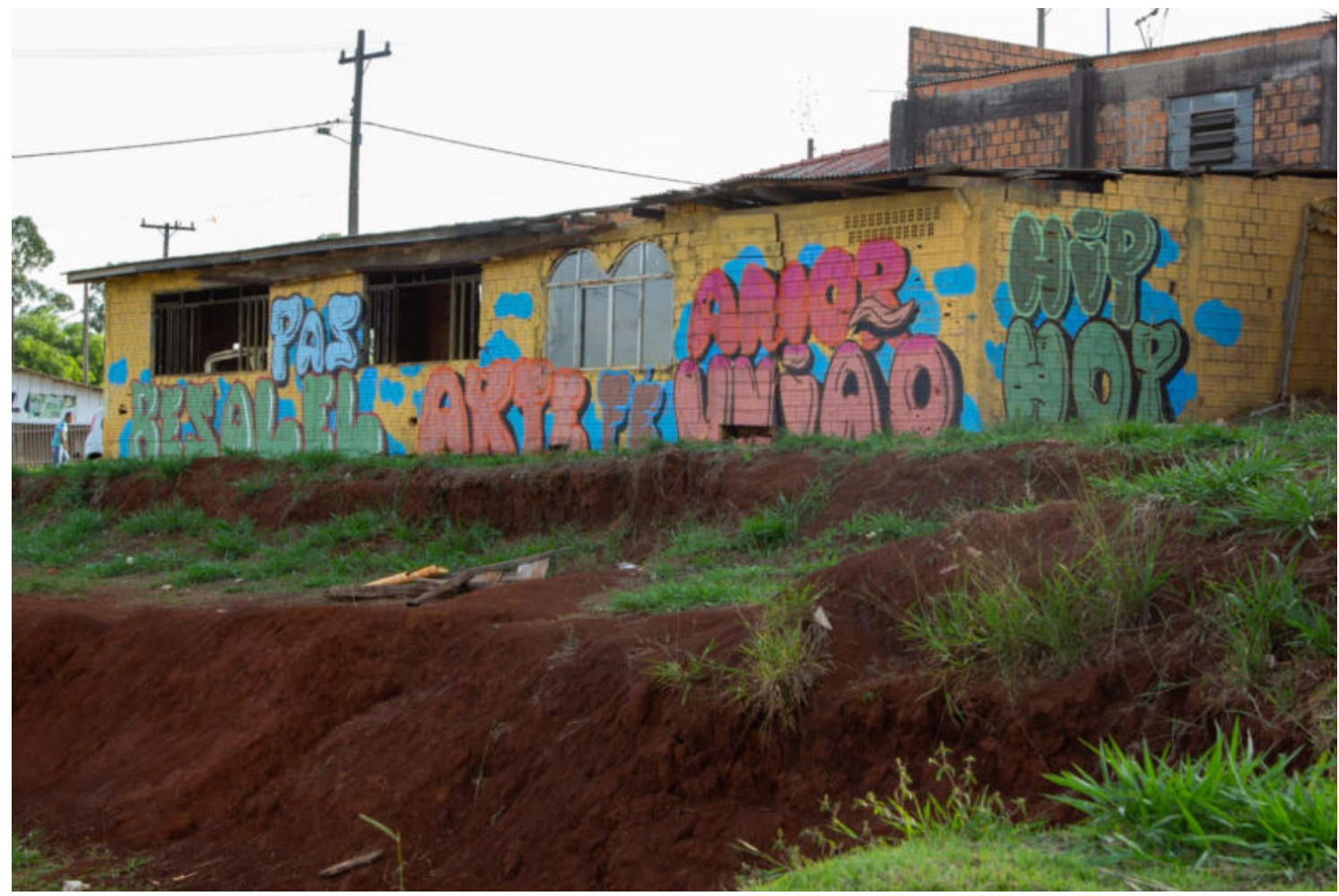



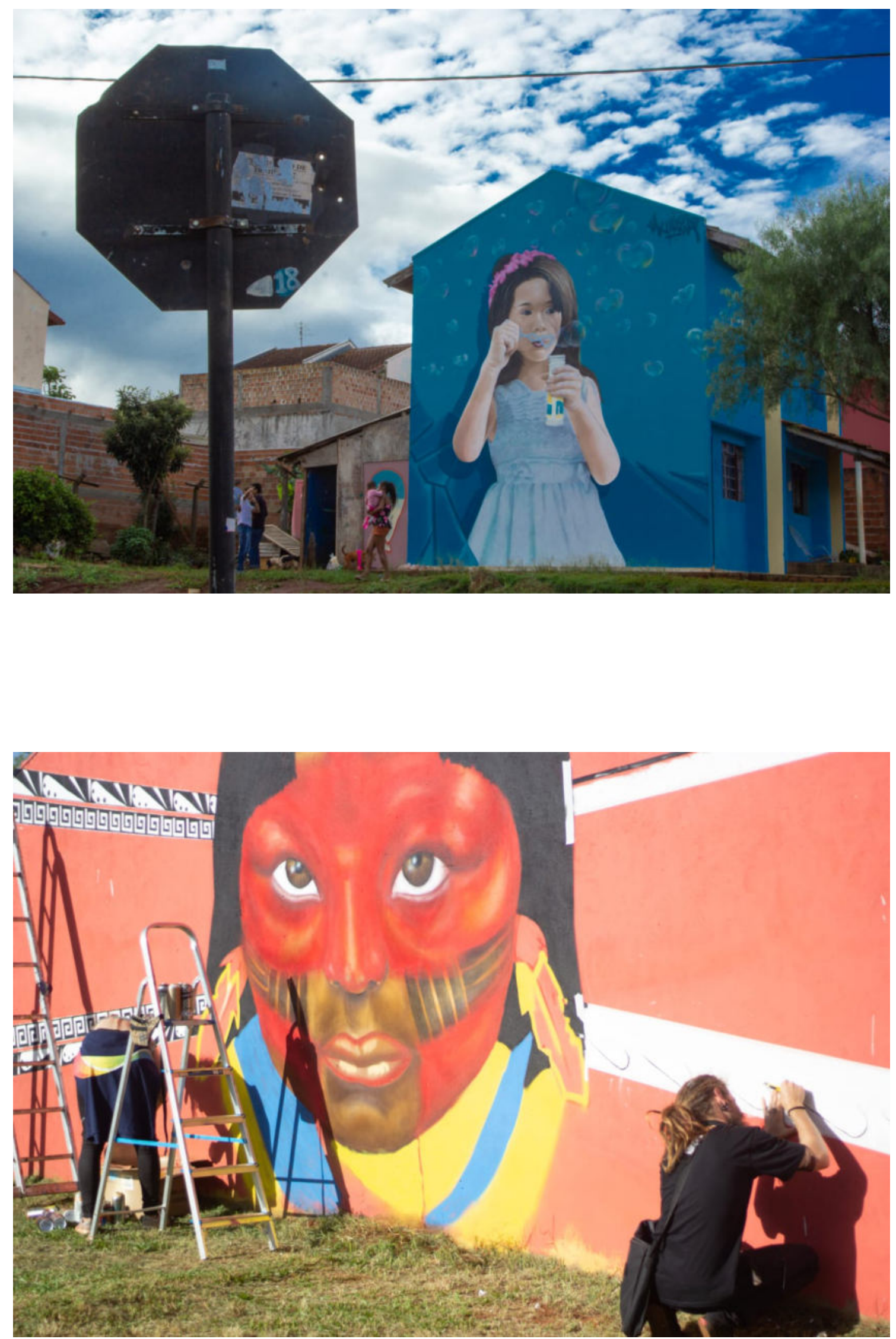


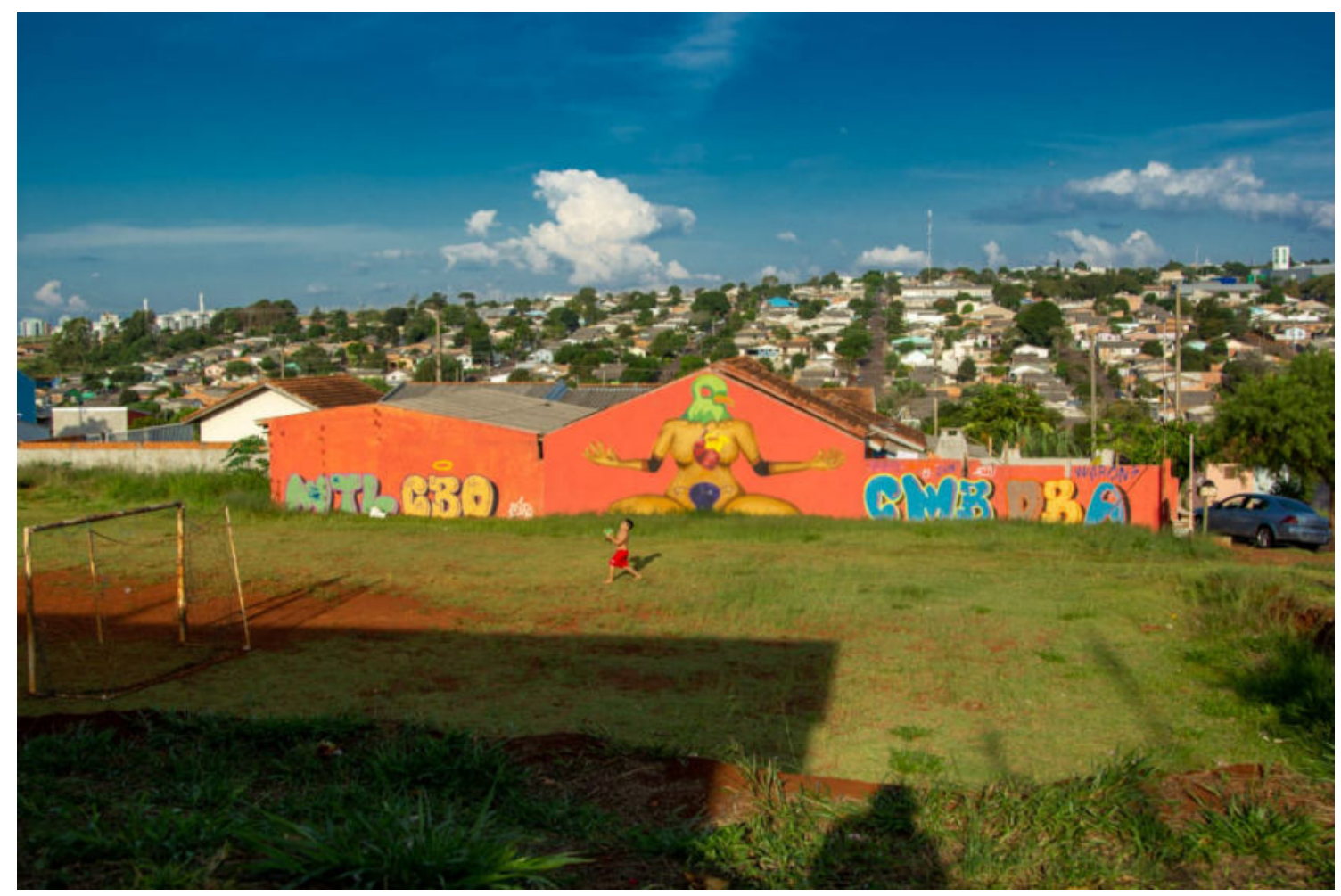



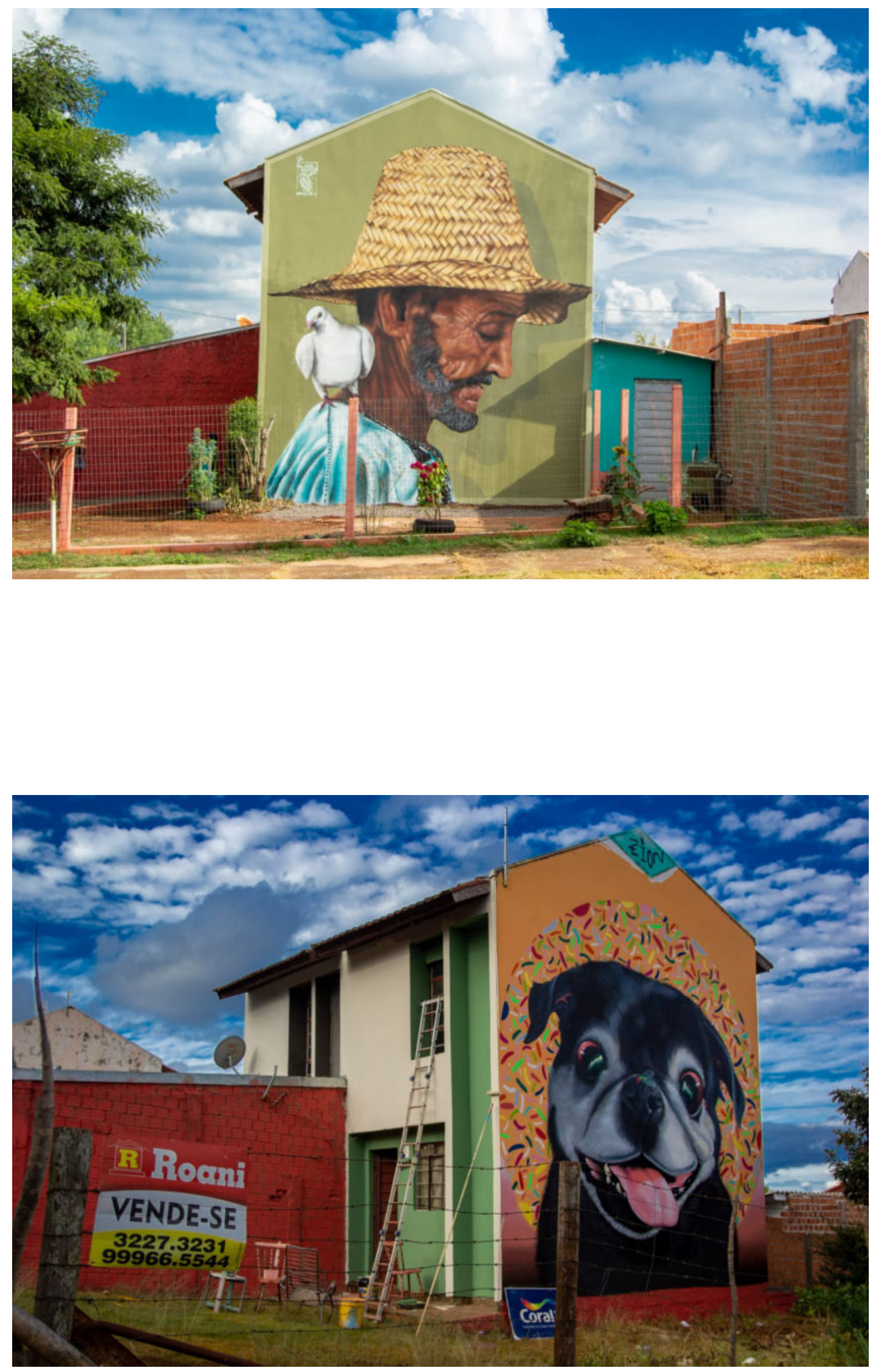


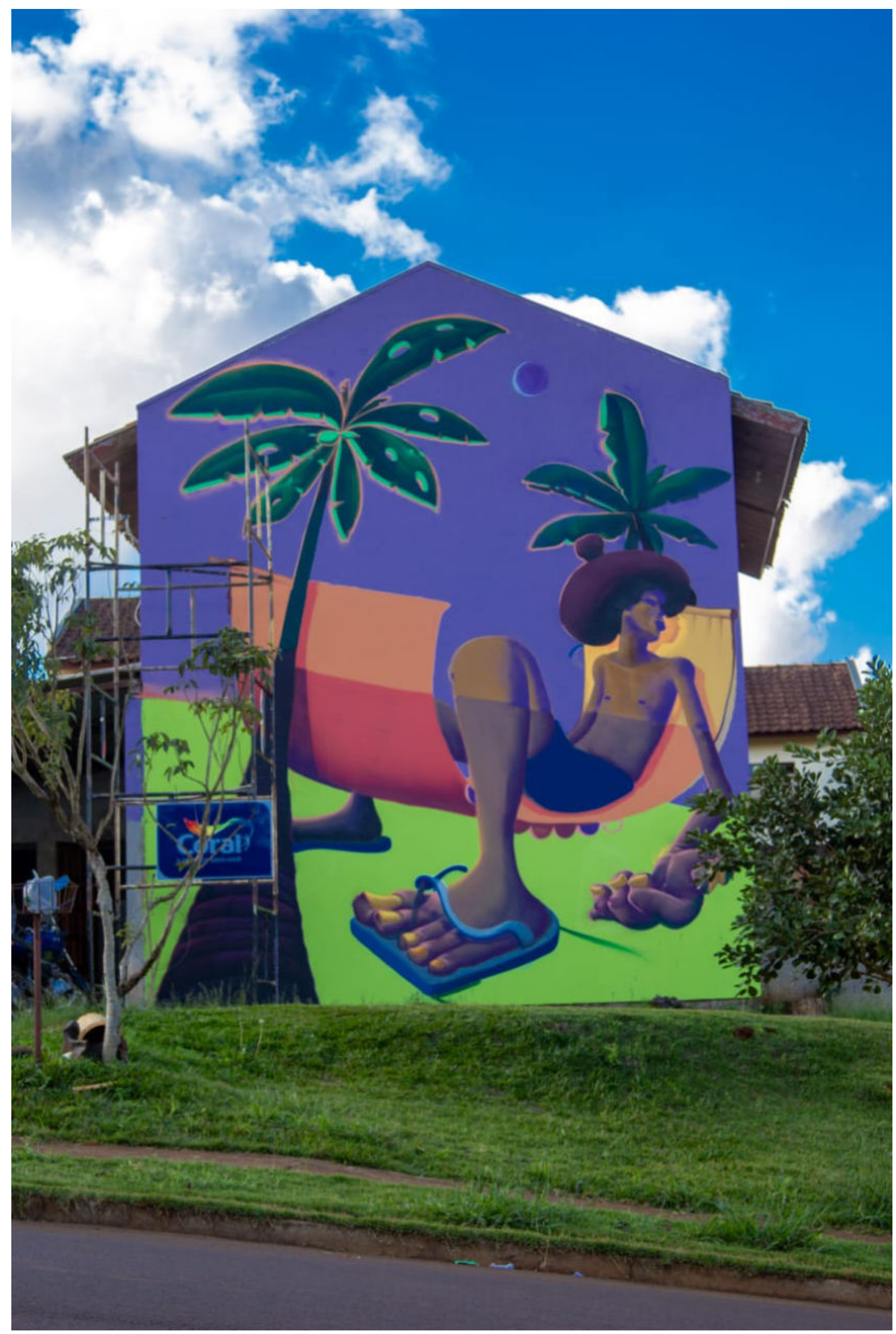



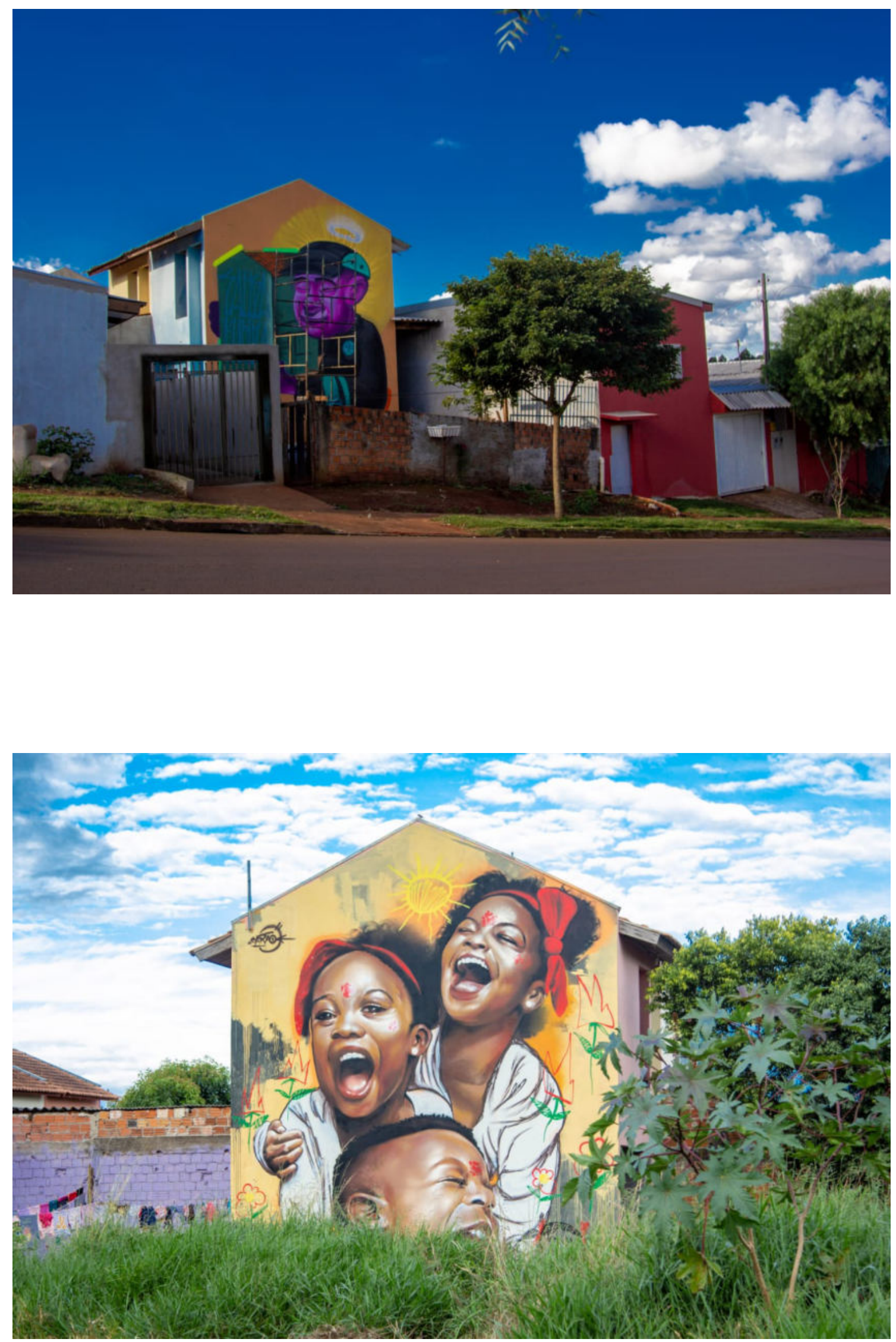


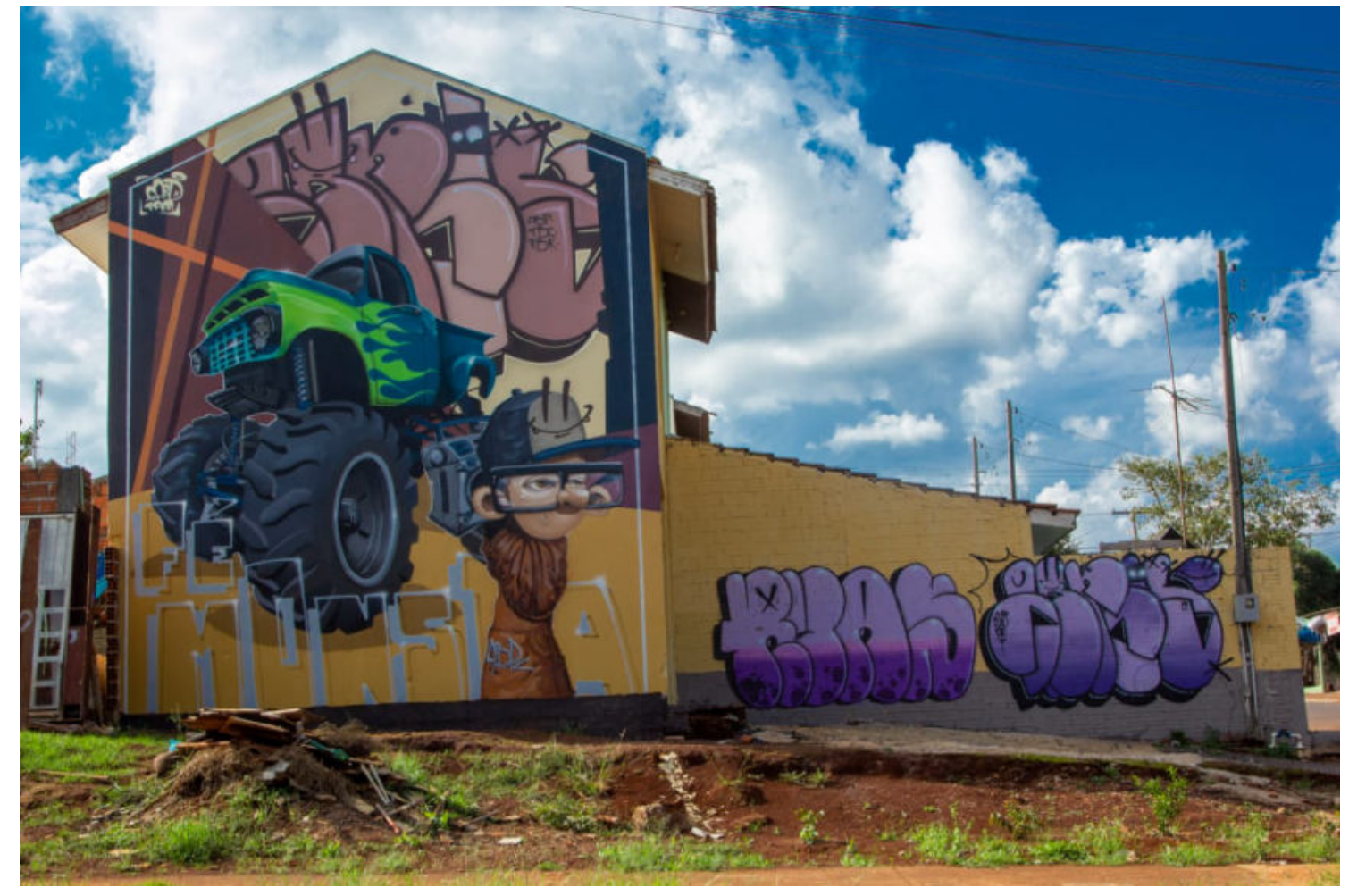



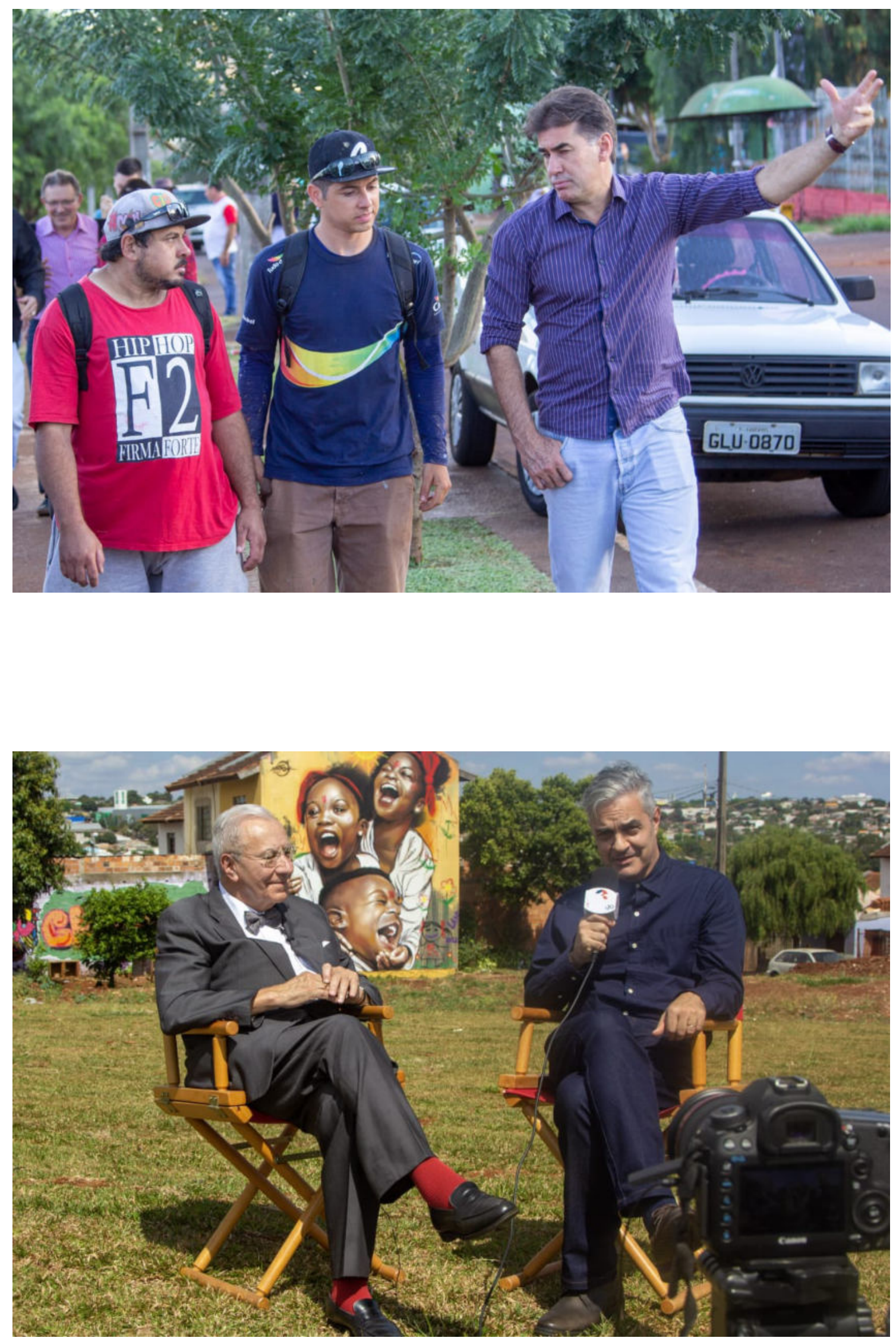

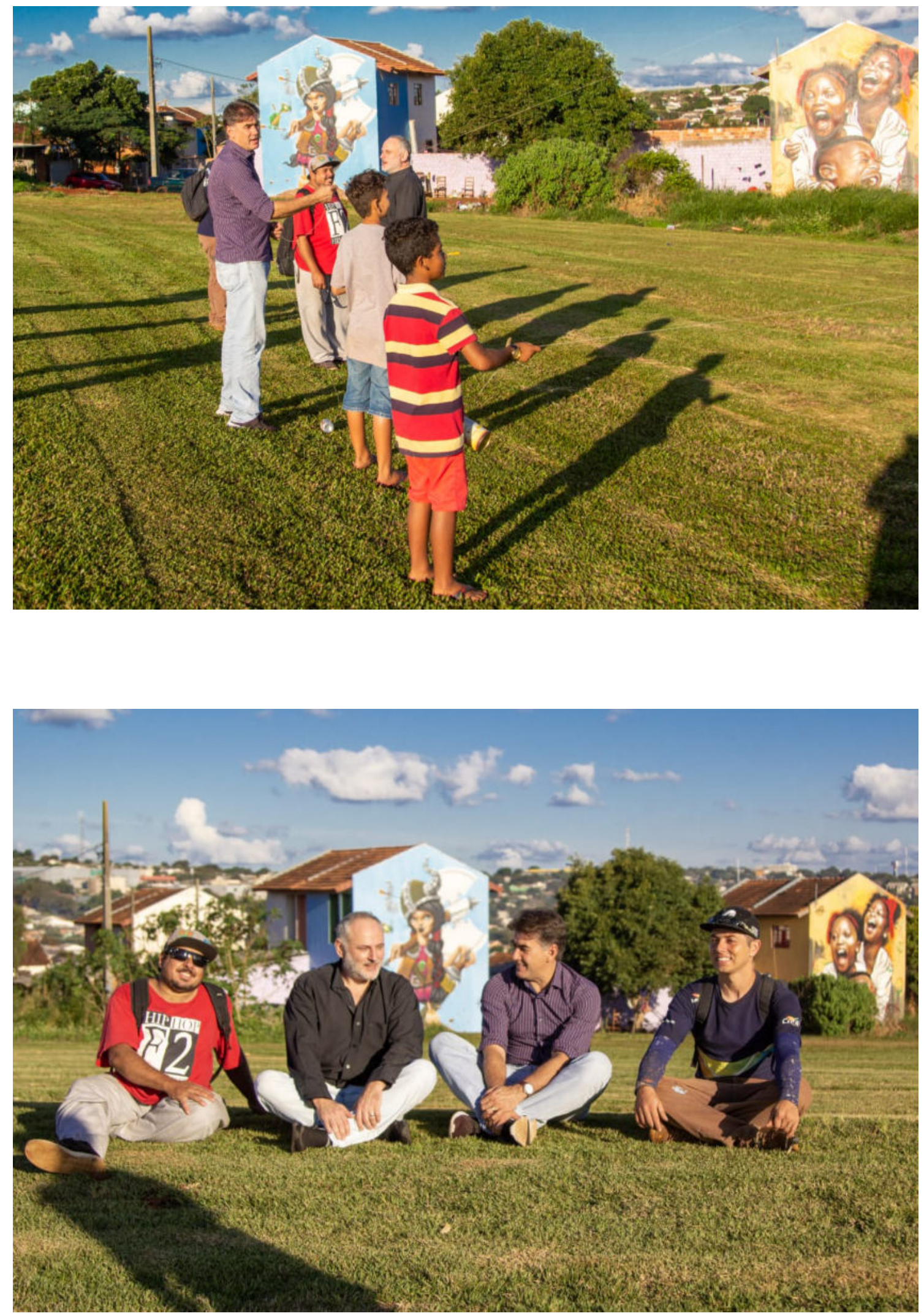


\section{REFERÊNCIAS:}

ACHUTTI, Luiz Eduardo Robinson. Fotoetnografia: um estudo de antropologia visual sobre cotidiano, lixo e trabalho. Porto Alegre: Tomo Editorial: Palmarinca, 1997.

Fotoetnografia da Biblioteca Jardim. Porto Alegre: Editora da UFRGS: Tomo Editorial, 2004.

HASSEN, Maria Nazare. Caderno de campo digital: antropologia em novas mídias. Horizontes Antropológicos. 21(10), 273-289. 2004.

ALVES, Fabio Lopes et al. An essay of visual anthropology on daily life of workers during the COVID-19 pandemic in Cascavel - PR, Brazil. Research, Society and Development, [S. l.], v. 10, n. 6, p. e26710615782, 2021. DOI: 10.33448/rsdv10i6.15782. Disponível em: https://rsdjournal.org/index.php/rsd/article/view/15782. Acesso em: 1 oct. 2021.

BARBOZA, Luiz Gustavo Santos. Análise da disposição a um negócio social pela população do conjunto habitacional Sanga Funda no município de Cascavel PR. Dissertação (Mestrado Profissional em em Administração). Universidade Estadual do Oeste do Paraná, 2017.

CIDADE, Daniela Mendes. Fotografia e construção narrativa: algumas reflexões a partir do projeto A Cara da Rua. Revista Arcos Design. Rio de Janeiro, V. 11 N. 1, janeiro 2018.

KOURY, Mauro Guilherme Pinheiro. A Imagem nas Ciências Sociais do Brasil: um balanço crítico. BIB-Revista Brasileira de Informação Bibliográfica em Ciências Sociais, Rio de Janeiro, n. ${ }^{\circ}$ 47, 1999a.

Imagem e memória: ensaios em Antropologia Visual. Rio de Janeiro: Garamond, 2001.

Imagem e narrativa - ou, existe um discurso da imagem? Horizontes Antropológicos, Porto Alegre, ano 5, n. 12, p. 59-68, dez. 1999b. 
Imagens \& Ciências Sociais. João Pessoa, Editora Universitária da UFPB, 1998.

. Universo das imagens. Educere et Educare. Cascavel, Vol. 9 n ${ }^{\circ} 17$ Jan./jun. 2014. 